\title{
A Review of Literatures Related of Using Kenaf for Pulp Production (Beating, Fractionation, and Recycled Fiber)
}

\author{
Ahmad Azizi Mossello (Corresponding author) \\ Institute of Tropical Forestry and Forest Products, University Putra Malaysia, Malaysia \\ Department of Desert Region Management, College of Agriculture, Shiraz university, Shiraz, Iran \\ E-mail: aziziahmad99@yahoo.com/azizi1353@gmail.com \\ Jalaluddin Harun \& Paridah Md Tahir \\ Institute of Tropical Forestry and Forest Products, University Putra Malaysia, Malaysia
}

Hossein Resalati

Faculty of Forestry and Wood Technology, Gorgan University of Agricultural and Natural Resources, Iran

Rushdan Ibrahim

Forest Research Institute Malaysia, Malaysia

Seyed Rashid Fallah Shamsi

Department of Desert Regions Management, College of Agriculture, Shiraz university, Shiraz, Iran

Ainun Zuriyati Mohmamed

Institute of Tropical Forestry and Forest Products, University Putra Malaysia, Malaysia

\begin{abstract}
This paper reviews several empirical studies which highlight the using of kenaf for pulp production (beating, fractionation, and recycled fiber). Kenaf is a non-wood pulp source that is alreadly used in parts of the world. Review studies showed that being a dicotyledonous plant, kenaf stem consists of bast and core fibers that are significantly different in chemical and morphological properties. Fiber properties directly influence pulping conditions applied in pulp and papermaking production. Kenaf fibers due to different nature and structure exhibit different behavior during pulping and papermaking. Core pulp due to presence of components with a high surface area coming from pith has low freeness and enhance susceptibility to refining action and pulp rapidly attains freeness value that are quite prohibitive for practical purposes. These short comings restrict the use of core pulp, which probably better used as unrefined. On the contrary, bast pulp refines easily and develops its strength. Due to difference in the quality of bast and core fiber, some researchers have proposed to fiber separation and pulping of each fraction separately and using each pulp lonely or blending refined bast pulp and unrefined core based on final product properties. These review results showed that, there is promised to use of kenaf as whole stem (bast and core together) for technical and economical advantages.
\end{abstract}

Keywords: Kenaf, Pulp Production, Beating, Fractionation, Recycled Fiber

\section{Introduction}

The genesis of using kenaf for pulp production dates back to the last century, with the work of by Watt in 1980. In the dictionary of economic plant India, Watt mentioned that the fiber of kenaf was used in Bengal for the production of pulp. He also noted that the paper made from kenaf fiber was superior in strength to the paper used in making bank of England note (Liu, 2002).

Kenaf was introduced to the United States during the 1940s as a substitute for jute (Fisher, 1994). In 1960, the United States Department of Agriculture (USDA) identified kenaf as the most promising of a wide variety of annual plants for paper making (Fisher, 1994; Nieschlag, et al., 1960). Experiments in producing kenaf as a raw materials for pulp in the United States showed that the unit costs would be about half of that used in the production 
of pulpwood and produce 3-5 times as much as dry materials for pulping per unit of land annually. USDA research on kenaf was cut off in the 70's when attention turned to energy crisis, but research continued in the private sector (Liu, 2002). The world's first commercial kenaf pulp mill known as Phoenix Pulp \& Paper Co. Ltd. was established at Khon Ken, Thailand in 1981. The pulp mill was initially based on whole stalk kenaf with an annual production capacity of 70,000tonnes (Mittal \& Maheshwari, 1994). Vision Papers in the U.S. is reported to have developed and commercializing 100\% kenaf made of chlorine free paper (Rymsza, 2001).

Kenaf is currently being explored in developed and developing countries as a viable raw material for pulp, paper and wood composite manufacturing. Japan has been the world major consumer of wood-fiber papers is keen on increasing its usage of non-wood fiber and is reported to have indicated its preference for kenaf as the preferred feedstock (Anonymous, 2009). India, China, and Thailand account for $90 \%$ of world plantation with more than $95 \%$ of world production of kenaf. In 2005-2006, total kenaf production was 0.33 million tons of which India, China and Thailand produced $42 \%, 25 \%$ and $11 \%$, respectively, while other countries produced the difference (FAO, 2006).

In Malaysia, kenaf was first introduced in the early 1970s and was recognized as a potential alternative fibrous material for the production of panel products such as fiberboard and particle board in the late 1990s under the $7^{\text {th }}$ Malaysian Plan1996-2000 (Abdul Khalil et al., 2010). Due to its potential commercial value, the government has allocated RM 12 millions for research and future development of kenaf - based industry under the $9^{\text {th }}$ Malaysian 2006-2010(Mohd Edeerrozey et al., 2007). Under the plan, the National Kenaf and Tobacco Board (LTN) contrive the development of kenaf cultivation in order to replace the current tobacco cultivation especially in the state of Kelantan. Moreover, the government also emphasizes diversifying and commercializing the downstream kenaf -based industries including the pulp and paper industry in cooperation with private sector.

\section{Beating}

The strength properties of a sheet of paper depend on its original qualities, strength of fibers and on the extent of bonding between fibers that make up the sheet. A paper sheet made from virgin pulp which has not undergone a form of mechanical treatment is characterized by low strength, bulkiness, surface roughness and not suitable for papermaking (Bhardwaj et al., 2004). These undesirable characteristics can be changed to a large extent by treating the pulp mechanically in a highly controlled manner. This mechanical treatment of fibers is termed beating (Bowyer et al., 2007; Bhardwaj et al., 2004). The beating of fibers consists of mechanical crushing and abrasion of fiber caused by contact with edge and faces of rapidly moving metal bars in the presence of polar penetrating liquid, such as water. Both mechanical and hydraulic forces are employed to alter the fiber characteristics. The major effects of beating on fiber include (Clark, 1985):

External fibrillation- the outer layer of the fiber bonds are removed, exposing fibrils of the secondary wall. New external surfaces are created, which can participate in polyelectrolyte adsorption and inter-fiber bonding.

Internal fibrillation- intra-fiber bonds are broken and the wall structure becomes more porous, enhancing water absorption, fiber swelling (hydration) and flexibility. The fiber wall swelling occurs inwards towards the lumen, with a corresponding decrease in lumen volume, while the other diameter of the fiber remains unchanged.

Fine formation- pieces of fiber wall depth from the fiber, creating secondary fine. These can consist of exposed cellulose fibrils from the secondry wall, and material from the primary wall and middle lamella, in case of high yield pulps.

Release of the chemical components- wood polymers and pulping chemicals may be released during the beating and may in themselves create a cationic demand in the pulp suspension.

All four effects occur simultaneously, but to different extents depending on the control of the variable in the beating process. The shortening of fibers improves sheet formation considerably, thus contributing to paper uniformity and smoothness. However, fiber shortening causes a large reduction in tearing and folding resistance of the resulting paper, a proportional reduction in the bursting strength, and small reduction in tensile strength. The action of crushing the fiber against each other, or between metal surfaces organizes the bundles of cellulose fibrils, near the surface to become free.

The newly exposed surfaces avidly interact with water molecules producing swelling and an increase in fiber surface. Both shortening and external fibrillation of the fibers produce free small fragments of cell wall called fines. Fines greatly reduce the drainage of water in paper formation by filling pores in the sheet, but provide at same time more fiber - fiber contact area. It is known that internal fibrillation separates bundles of fibrils located in the interior of cell wall of fibers without causing generation of fines. Water is then able to reach the new surfaces producing swelling and separating individual interior fibrils (hydration). As a result of the internal fibrillation, the 
fiber becomes plasticized and more deformable, improving fiber - fiber contact area when pressed and dewatered (Clark, 1985).

Beating or refining of pulp is an essential process of paper manufacture and is carried out to a greater or lesser degree in all paper and board mills. On the other hand, some variables such as fiber properties, equipment characteristics and process variables affect refining process and final pulp and paper properties. Hence a lot of research carried out to understand the relation between these variables.

The members of the Institute of Paper Chemistry (1944), under the leadership of Van den Akker, presented a theory for procedure of tear. Van den Akker explained that the initial rise in the tearing strength/ beating - time curve is due to that fact that in the initial stages of beating, the frictional drag work increases by virtue of tighter enmeshment caused by slightly increased bonding. During this time only a negligible number of fibers fail in tensile rupture. As the beating continues, more fibers fail in tensile rupture and therefore, fewer fibers are pulled intact from the mesh. Since the frictional drag force per fiber is much greater than the rupture work, this decrease in the number of fibers pulled intact from mesh causes the tear strength to decrease.

Watson\& Dadswell (1964) studied the influence of fiber morphology on paper properties and indicated the prime importance of fiber length and confirmed the existence of a critical level of bonding. In short fiber pulp, this critical level of bonding is never attained in unbeaten pulp, and only rarely in beaten pulp, so that the tear factor increases with beating. The distribution of stress is less widespread than with long fiber pulp, and the energy required to pulp out the unbroken fibers is relatively low, thereby giving rise to a low tear value. In long fiber pulp the degree of bonding before any beating is generally above this critical level, and any increase in bonding which results in the reduction of the area of stress concentration, thereby reducing the amount of energy required in rupturing the paper.

Koning \& Haskell (1979) evaluated the effects of several papermaking factors- wood species, pulp yield, type of refiner, amount of refining, wet-press pressure and surface on strength properties of linerboard weight hand sheets and found that wet press pressure, wood species, degree of refining and yield were most important. The degree and direction of the change depend on the particular property. For example, for ring crush, freeness and wet- press pressure were significant factors for burst, four factors (species, yield, freeness and pressure) and one interaction (species- yield).

Maddern \& Franch (1989) studied the main papermaking properties of bleached soda-AQ kenaf bark and core pulp. They found that the bark fibers are long, thin and stiff giving good tear and light scattering and moderate bonding. They produce a bulky sheet with good bonding stiffness. Core fibers are short and wide with thin walls so that they collapse readily, with little beating, producing a dense, very smooth and stiff well bonded sheet with good optical properties. The woody core is difficult to pulp and the pulps, partially in regarded to tears, are lower quality. Morever the pulps have slower drainage characteristics than wood pulps made by the same processes and beating. It can be used in special circumstances where low beating requirement and good smoothness are important.

Schroeter (1994) pulped both kenaf bast and core fibers using a soda-AQ process for linerboard. He found that the use of kenaf core fiber pulp in place of hard wood pulps improved sheet smoothness. The bast pulp required only minimal refining while the core pulp required no refining at all. The letter, when utilized as the top sheet in linerboard, resulted in reduced energy cost due to refining and improved sheet smoothness, without negatively impacting the sheet strength properties.

Pande and Roy (1998) studied the influence of fiber morphology and chemical composition on the papermaking potential of kenaf fibers and reported that hemicelluloses are important for internal cohesion of the cell wall, and their removal weakens the fiber by reducing inter-fiber adhesion. The removal of hemicellulose results in the replacement of the relatively flexible cellulose- hemicellulose-cellulose bonds by more rigid cellulose-cellulose bonds, thus inhibiting the stress distribution, and resulting in lowered strength properties. The beating energy required to develop a desired tensile strength decreases with increasing hemicellulose in pulp.

Seth (2001) studied the physical properties and response to the refining of never- dried and dried kraft pulps and reported that never dried pulps require less energy to reach a given freeness. Although never-dried pulps produce wetter web than those from dried pulps, the webs are stronger. At a given refining energy or freeness, never-dried pulps produce better bonded sheets. These differences are ascribed to the higher swelling and conformability of never-dried fibers.

Rushdan (2003) studied the effect of refining on fiber morphology and drainage time of soda pulp derived from oil palm empty fruit bunches and found that all fiber dimensions decreased as the degrees of refining increased. Fiber curling index had the largest decrease, while fiber lumen width had the smallest. Drainage time increased as the 
refining degree increased due to increase in fiber shortening and fine production.

Parker et al. (2005) studied the effect of network variables on the ring crush strength of NSSC pulps from three eucalyptus species and reported unrefined pulps due to low collapsed fibers produced sheets with ring crush strength. Refining with increasing flexibility of fiber, generation of secondary fines and fibrillation of the fiber promotes the formation of fiber- fiber bonds and thus leads to increase in ring crush strength.

Wanrosli et al. (2005) studied upgrading of recycled paper with oil palm fiber soda pulp and reported that as little as $20 \%$ addition of unbeaten virgin pulp and considerably lesser amount of ca. $10 \%$ of beaten virgin pulp is sufficient to completely restore the tensile strength of recycled fiber. The major mechanism of strength improvement is probably due to the increase of inter fiber bonding as a result of substitution of inactive secondary fibers with active virgin fibers. With addition of beaten pulps, the effect is even more remarkable. This enhancement is ascribed to the increase in the bonded area of sheet resulting from internal and external fibrillation that occurs during beating.

Bhardwaj et al. (2007) studied the influence of refining on physical and electrokinetic properties of various cellulosic fibers and found that beating increases the surface charge, specific surface area and specific volume of fibers, but did not change the total fiber charge. When beating to the same freeness, the pine kraft pulp had higher surface charge, surface area, and specific volume than eucalyptus pulps. Also, the eucalypt pulps were much easier to beat than pine pulps. Increasing surface area by refining resulted in a higher surface charge and better fiber fiber bonding.

Yang et al. (2008) studied the effect of fungal treatment on eucalyptus chemitheromechanical pulp properties and reported that in comparison with the control pulp, fungal treated pulps were easier and need less energy to be refined for a target freeness level and produced paper with higher strength properties and lower light scattering coefficient that indicates fungal treatment causes some internal fibrillation of fiber and improves the fiber flexibility, which could enhance the fiber- fiber bonding capacity.

Villar et al. (2009) studied kenaf for kraft pulping and reported that the property of core and bark kraft pulp differ distinctly. Bark pulp produced bulky sheets that were extremely resistant to tear by virtue of the high length of the fibers. Although their burst and tensile indices are lower than those of unrefined core pulps, bark pulps refine easily and develop its strength properties. On the contrary, core pulps, with much less initial freeness could not be refined without causing difficulties in drainage.

Jahan et al. (2009) studied the pulpability within jute plant and reported that core pulp due to shorter fiber and higher hemicellulose content were easier to beat than bark and whole plant pulps and produced paper with good properties except tear index. Jahan \& Rawshan (2009) compared the refining capacity and papermaking properties of jute fiber and Nalita (Trema orientalis) pulps and reported that for a given drainage resistance, Nalita pulp required less refining energy than that of jute fiber pulp. Both pulps showed liner relationships between drainage resistance and refining level. The tensile and burst index of both pulps rapidly developed (drainage resistance ${ }^{\circ} \mathrm{SR}$ 10-30) until they leveled off at moderate level of drainage resistance.

\section{Fractionation}

The plant for papermaking is made of fibers that differ greatly in morphological properties. The fiber morphology determines the final paper properties to a great extent, so that have been shown to explain the 70 to $90 \%$ paper properties variation (Dinwoodie, 1966; Barefoot et al., 1964). However, the traditional approach of preparing fibers for papermaking is to pulp the plant and process the fiber as a collective. This approach simplifies the process design, but neglects the opportunity to exploit the inherent benefits of the individual fiber fractions (Gooding \& Olson, 2001).

Fiber Fractionation processes, which utilizes maximum potential of the fiber, are becoming increasingly important in paper industry (Sood et al., 2005). It is a process that segregates a blend of pulp fibers into two or more streams based on some physical properties such as length, flexibility, coarseness etc (Sood et al., 2005; Gooding \& Olson, 2001). Fractionation and consequent selective processing (or use) of furnish components offers potential to achieve raw material and energy efficiency. The idea is to direct the right kind of fiber furnish and through the processing it requires and ultimately to the end user, where it will generate the highest customer value. This offers the paper makers options to produce paper with optimum properties for specific application by controlling the refining conditions, use of additives, dewatering conditions at the wet end and draws in the dryer section (Sood et al., 2005). For instance, after fractionation of pulp in two fractions, it can be used according to one of the following schemes: (a) utilization of the two fractions in the production of two different grades on separate machines, (b) utilization of the two fractions in two or more plies in the same sheet or paper, (c) remixing the beating long fiber 
fraction with unbeaten short fraction (Howard, 1991). A pulp producer, for example, with two pulp machines, could fractionate the fibers and increase the content of the long fibers on one machine to provide a high-value reinforcing pulp. Alternatively a paper producer with a multi-layer head box could direct the shorter fibers to the surface layers to improve sheet smoothness, while placing the longer fibers in the feed to core to provide strength. Within the mill system, one could concentrate long, stiff fibers in the feed to reject refiner to save energy and increase capacity, while avoiding the degradation of fibers that are already acceptable (Gooding \& Olson, 2001).

Being a dicotyledonous plant, kenaf stem consists of bast (35\%) and core fibers that are significantly different in chemical and morphological properties (Ashori et al., 2006). Fiber properties directly influence pulping conditions applied in pulp and papermaking production. Kenaf fibers due to different nature and structure exhibit different behavior during pulping and papermaking processes (Villar et al., 2009; Sharmiza et al., 2005; Khristova et al., 2002; Ohtani et al., 2001; Khristova et al., 1998; Ren et al., 1996; Calabro, 1992; Kaldor, 1989).

Core pulp due to presence of components with a high surface area /mass ratio coming from pith (Villar et al., 2009) has low freeness and enhance susceptibility to refining action and pulp rapidly attains freeness value that are quite prohibitive for practical purposes(Calabro, 1992). These shortcomings restrict the use of core pulp, which probably better used unrefined (Kaldor, 1989). On the contrary, bast pulps refine easily and develop its strength (Villar et al., 2009; Calabro, 1992). Due to difference in the quality of bast and core fiber, some researcher propose to fiber separation and pulping of each fraction separately (Calabro , 1992; Kaldor, 1989,) and use each pulp lonely or blending refined bast pulp and unrefined core based on final product properties (Villar et al., 2009). On the other hand, there is promised to use of kenaf as whole stem (bast and core together) for technical and economical advantages (Ververis et al., 2004; Khristova et al., 2002).

Although there are great benefits in fractionation and consequent selective process particularly in the improvement of pulp and paper properties( Table 1), however there is not published document to assess the effect of fractionation and consequent selective process on kenaf pulp and paper properties.

\section{Recycled Fiber}

Recycling of various materials has come under increasing spotlight as the environmental awareness of the general public increases. Recycling is associated with a clean green image and industries are under pressure more than ever before to perform in this area. Pulp and paper manufacturing is no exception to this recycling trend (Carstens, 2008). Recycled paper has become commercialized since 1800 while serious investigation on it only started in the late 1960s (Howard, 1991). Generally, these investigations can be divided into four categories: recycling operation, environment protection, product performance, and sheet properties. Research on sheet properties incorporates new pulps, causes of lost quality, recovering or upgrading of quality and effect of recycling unit operation Howard (1990).

Paper strength with randomly oriented fibers is dependent on the strength of the individual fibers and the strength and number of the bonds between them (Page, 1969). The strength of the individual fiber is not changed by mechanical processing during papermaking process (Clark, 1985; Paavilainen, 1991), but the strength and number of the bonds between fibers change by mechanical process (Stratton \& Colson, 1990). Paper made of recycled fibers has different qualities from paper made of virgin fibers. The effects of recycling on physical properties vary greatly depending on the pulp type and the process it has undergone (Wanrosli et al., 2005; Minor et al., 1993). In general, the papermaking properties of fibers deteriorate with the extent of recycling. This behavior was attributed to the degradation in fiber bonding (Garg et al., 2008; Wanrosli et al., 2005).

During a drying and rewetting cycle, the fiber lost their conformability and swelling capacity associated with the phenomenon of irreversible hardening or hornification. The hornification occur when the hydrogen bonds that were formed between cellulose chains in the cell wall during drying resist been broken during the rewetting process, resulting in only partial swelling since some chains remain bonded (Wanrosli et al., 2005; Seo et al., 2002; Minor et al., 1993). Hornified fibers are stiffer because of internal collapse and more resistant to fibrillation due to collapse. Mechanical pulps are normally less susceptible to hornification than are bleached chemical pulps because the lignin content restricts the opportunity for intermolecular mobility and contact within the carbohydrates component. Also, fibers with high lignin content are initially more rigid because of the three dimensional structure and cross - linking characteristics of the lignin macromolecule, which result in less initial fiber collapse and bonding (Seo et al., 2002; Minor et al., 1993).

Although the effects of recycling on paper quality are known, a complete understanding of how to recover or minimize the loss of recyclability of secondary fibers is not known (Wanrosli et al., 2005). Various methods have been suggested and used in practice. The notable ones are mechanical refining, chemical additives, physical fractionation( discribed in section 3), and blending. Each method has its own advantages and disadvantages. 
Refining enhances papermaking properties of recycled fiber by increasing fiber flexibility and swell ability which were lost during fiber drying (Seth, 2001; Minor et al., 1993; Howard \& Bichard, 1992), but generation of fines and reduction in pulp freeness are draw backs of this operation (Garg et al., 2008; Mocciutti et al., 2008). Moreover, if in a commercial operation, the wastepaper supply contains mechanical pulp, the situation is worsened, because the fibers of mechanical pulp are very easily broken up by refining (Howard, 1991).

Starch, gum and other dry strength-enhancing agents are well known and added to recycled fiber furnish to compensate for the loss in original strength. Considerable interest has been shown in recent years for the development of dry strength additives having improved efficacy (Ren et al., 2009; Ekhtera et al., 2008; Che et al., 2003; Kitaoka \& Tanaka, 2001) but they can not be used as full substitute to refining as they can not restore the swelling ability of hornified fibers, and the penetration of their large molecules into micropores in the cell wall structure is limited (Christiane et al., 2000).

Blending of virgin pulp with recycled fibers offers another viable option for upgrading the recycled pulps. Many studies have shown the strength enhancement of recycled fiber by adding virgin pulps (Latifah et al., 2009; Garg et al., al., 2008; Wanrosli et al., 2005; Rushdan, 2003; Aravamuthan et al., 2002; Dell \& Paul, 1998; Horn et al., 1992). The major mechanism of strength improvement is probably due to increase of inter fiber bonding as a result of substitution of inactive secondary fibers with active virgin fibers (Wanrosli et al., 2005). However the strength properties of pulp blends are not simply the average of the strength properties of their component. Depending on the nature of the components and the specific property of interest, they may well be positive or negative deviations from the average (Rushdan, 2003). It is very important to optimize the amount of virgin pulp in blend with recycled fibers to reach appropriate properties.

Mills occasionally use softwood fibers to impart additional strength to paper made from recycled paper (Mas'ut, 2009, Dehghani Friouzabadi et al., 2008; Wanrosli et al., 2005) but softwood pulp is expensive (Dutt et al., 2009; Jahan \& Rawshan, 2009) and new legislations enacted in response to the demand from environmentalists in various countries have restricted the cutting of trees. On the other hand, kenaf has been identified as a suitable reinforcement pulp (Latifah et al., 2009; Dehghani Friouzabadi et al., 2008; Aravamuthan et al., 2002). But these researches has used bast lonely or with higher percentage in bast/core mix that increased cost incurred in separation cost and reduce fiber production per hectare that cancels one of the theoretical advantages of kenaf (Villar et al., 2009).

\section{Conclusion}

This paper reviews several empirical studies which highlight the using of kenaf for pulp production. The increase in world population coupled with industrialization has amplified the demand for paper and paperboard. Non-wood fibers or alternative fibers refer to non-woody cellulosic plant materials used for papermaking. The overall conclusion is that, in order for kenaf to compare wood as sources of papermaking raw materials, the cost of fiber supply and processing must be minimized. Using the whole stem, rather than separating the kenaf into the bast and core fractions may reduce fiber supply costs for kenaf significantly which would represent a problem for commercialization of this raw material. The extra processing steps involved in separation, and extra cost of two pulping lines keep kenaf from competing effectively with wood. As discussed above demonstrate that in most respects (strength properties, drainageability) whole stem are most favorable for pulp and paper production or OCC improvement. Thus kenaf is currently been explored in developed and developing countries as a viable raw material for pulp and paper.

\section{References}

Abdul Khalil, H. P. S., Ireana Yusra, A. F., Bhat, A. H., \& Jawaid, M. (2010). Cell wall ultrastructure, anatomy, lignin distribution, and chemical composition of Malaysian cultivated kenaf fiber. Industrial Crops \& Products, 31(1), 113-121.

Anonymous. (1993). State of Canada's Forests, Published by Natural Resources Canada-Canadian Forest Service, Ottawa. (pp. 112).

Anonymous. (2009). Paper, printing \& the environment. Assessed on Wednesday 31st March, 2010 from http://www.earthgreetings.com.au/htm\%20pages/environment/paper\&environment.html.

Aravamuthan, R., Lechlitner, J., \& Lougen, G. (2002 ). High yield pulping of kenaf for corrugating medium. Paper presented at the TAPPI, Fall Technical Conference.

Ashori, A., Jalaludin, H., Raverty, W.D., Mohd Nor, M.Y. (2006). Chemical and morphological characteristics of Malaysian cultivated kenaf (Hibiscus cannabinus) fiber. Polymer-Plastics Technology and Engineering, 45, 131-134. 
Barefoot, A. C., Hrrchings, R. G., \& Ellwood, E. L. (1964). Wood characteristics and kraft paper properties of few selected loblolly pines. I. Effect of fiber morphology under identical cooking conditions. TAPPI JOURNAL, 47(6), 57-66.

Bhardwaj, N. K., Duong, T. D., \& Nguyen, K. L. (2004). Pulp charge determination by different methods: effect of beating/refining. Colloids and Surfaces, 236, 39-44.

Bhardwaj, N. K., Hoang, V., \& Nguyen, K. L. (2007). A comparative study of the effect of refining on physical and electrokinetic properties of various cellulosic fibres. Bioresource technology, 98(8), 1647-1654.

Bowyer, J. L., Shmulsky, r., \& Haygreen, J. (2007). Forest products and wood science an introduction (5th ed.): Blackwell Publishing Asia.

Calabro, G. (1992). Kenaf pulp properties as a function of thier composion, yield and freeness. Paper presented at the Tappi Pulping conference.

Carstens, J. (2008). Technology in fibre recovery Appita Journal, 61 (3), 186-191.

Che, D., Long, Z., \& He, Q. (2003). Study on improving strength of packaging paper made from OCC Guoji Zaozhi/World Pulp and Paper, 22(3), 32-34.

Christiane, A., Gottsching, L., \& Pakarines, H. (2000). Recycled fiber and deinking, Finland.

Clark, J. A. (1985). PulpTechnology and Treatment for Paper (2nd ed.). San Francisco: Miller-Freeman.

Dehghani Firouzabadi, M., Tavasoli, A., \& Mahdavi, S. (2008). Repalcing imported long fiber pulp with kenaf bast fiber soda pulp to improve quality of paper made from bagasse soda pulp. Iranan Journal of Wood and Paper Science Research, 23(2), 157-168.

Dell, B. A., \& Paul, K. R. (1998). Market kraft refining and influences on three OCC furnishes. Paper presented at the APPITA Annual General Conference.

Dinwoodie, J. M. (1966). The influence of anatomical and chemical characteristics of softwood fibers on properties of sulphte pulp. TAPPI JOURNAL, 49(2), 57-66.

Ekhtera, M., Rezayati Charani, P., Ramezani, O., \& Azadfallah, M. (2008). Effect of poly-aluminum chloride, starch, alum, and rosin on the rosin sizing, strenght, and microscopic appearance of paper prepared from old corrugated container (OCC) pulp. Bioresource, 3(2), 383-402.

FAO. (2006). Jute, Kenaf, Sisal, Aabaca, Coir and Allied Fibers Statistics, http://www.fao.org/es/esc/en/20953/21005/highlight_51023en.html.

Fisher, G. (1994). Availability of kenaf fibers for the U.S paper industry. Paper presented at the Tappi puping conference proceeding, book 2, November 6-10, Sheroton harbor island, San Diego, California, Tappi press, Atlanta, GA, USA.

Garg, M., Gautam, A.K., Singh, S.P. (2008). Wheat straw pulp as reinforcing aid for recycled softwood pulp. IPPTA Journal, 20(2), 113-117.

Gooding, R. W., \& Oslan, J. A. (2001). Fractionation in a bauer-menett classifier. Journal of Pulp and Paper Science, 27(12), 423-428.

Howard, R. C. (1991). The effect of recycling on paper quality. Paper Technology, 32(4), 20-25.

Howard, R. C., \& Bichard, W. (1992). The basic effects of recycling on pulp properties. Journal of Pulp and Paper Science, 18(4), J151-J159.

Jahan, M. S., \& Rawshan, S. (2009). Reinforcing potential of jute pulp with trema orientalis (Nalita). Bioresources, 4(3), 921-931.

Kaldor, A. F. (1989). Preparation of kenaf bark and core fibers for pulping by the Ankal method. Tappi, 72, 137-140.

Khristova, P., Bentcheva, S., Karar, I. (1998). Soda-AQ pulp blends from kenaf and sunflower stalks. Bioresource Technology, 66, 99-103.

Khristova, P., Kordsachia, O., Patt, R., Khider, T., \& Karrar, I. (2002). Alkaline pulping with additives of kenaf from Sudan. Industrial Crops \& Products, 15(3), 229-235.

Kitaoka, T., \& Tanaka, H. (2001). Novel paper strength additive containing cellulose-bonding domain of cellulose. Journal of Wood Science, 47(4), 322-324. 
Koning JR, J. W., \& Haskell, J. H. (1979). Papermaking factors that influence the strenght of linerboard weight handsheets (No. Research Paper FPL 323): Forest Products Laboratory and Forest Service U.S Department of Agriculture.

Latifah, J., Ainun, Z. M. A., Rushdan, I., \& Mahmudin, S. (2009). Restoring Strength to Recycled Fibres by Blending with Kenaf Pulp. Malaysian Journal of Science, 28(1), 79-87.

Liu, A. (2002). World Production and Utilization of Jute, Kenaf, and Allied Fibers. http://www.chinaconsulting.com/kenafworkshop.htm. Accessed on 8th March 2009.

Maddern, K. N., \& French, J. (1989). Papermaking properties of some Australian non-wood fibers. Appita Journal, 42(6), 433-437.

Mas'ut, A. s. (2009). Kenaf: A potential fiber for paper packaging industry. Paper presented at the International Conference on Kenaf and Allied Fibers Kuala Lumpur.

McClosky, J. T. (1995). What about non-woods? Paper presented at the Tappi symposium on global fiber supply, Atlanta, USA.

Minor, J. L., Tim Scott, C., \& Rajai, H. A. (1993). Restoring bonding strenght to recycled fibers. Paper presented at the Recycling Symposium, February 28- March 1-4; New Orleans, LA, Atlanta.

Mital, S. K., \& Maheshwari, S. (1994). A few technical aspects of pulp production from kenaf. Paper presented at the Pulping Conference, San Diego.

Mohd Edeerozey, A. M., Akil., H. M., Azhar, A. B., \& Zainal Ariffin, M. I. (2007). Chemical modification of kenaf fibers. Materials Letters, 61, 2023-2025.

Nieschlag, N. J., Nelson, G.H., Wolf, I.A., Perdue, R.E. (1960). A search for new fiber crops. Tappi, 43(3), 193-201.

Ohtani, Y., Mazumder, B. B., \& Sameshima, K. (2001). Influence of the chemical composition of kenaf bast and core on the alkaline pulping response. Journal of Wood Science, 47(1), 30-35.

Paavilainen, L. (1991). Influence of morphological properties of softwood fibers on sulphate pulp fibers and paper properties. Paper presented at the International Paper Physics Conferenc. Book 2, Tappi.

Page, D. H. (1969). The theory for tensile strength of paper TAPPI JOURNAL, 52(4), 674-681.

Pande, H., \& Roy, D. N. (1998). Influence of fiber morphology and chemical composition on the papermaking potential of kenaf fibres. Pulp and Paper Canada, 99(11).

Parker, I. H., Conn, A., \& Jackson, T. (2005). The effect of network variables on the ring crush strength of handsheets. Appita journal, 58(6), 448-454.

Ren, J. L., Peng, F., \& Sun, R. C. ( 2009). The effect of hemicellulosic derivatives on the strength properties of old corrugated container pulp fibres Journal of Biobased Materials and Bioenergy, 3(1), 62-68.

Ren, W., Du, H., Zhang, M., \& Ni, Y. (1996). Characterization of Chinese kenaf bark fibers for production of bleached chemical pulp. IPPTA, 8(2), 1-7.

Rodríguez, A., Moral, A., Serrano, L., Labidi, J., \& Jiménez, L. (2008). Rice straw pulp obtained by using various methods. Bioresource technology, 99(8), 2881-2886.

Rushdan, I. (2003). Effect of refining on fibre morphology and drainage of soda pulp derived from oil palm empty fruit bunches. Journal of Tropical Forest Products, 9(1/2), 26-34.

Rushdan, I. (2003). Structural, mechanical and optical properties of recycled paper blended with oil palm empty fruit bunch pulp. Journal of Oil Palm Research, 15(2), 29-35.

Rymsza, T. A. (October, 2001). Commercial paper making with kenaf. Paper presented at the PIRA Nonwoods Conference, Amesterdam, NL.

Schroeter, M. C. (1994). Use of kenaf for linerboard quality enhancement. In: Proceeding. Paper presented at the Pulping Conference, San Diego.

Seo, Y. B., Kim, D., Lee, J. H., \& Jeon, Y. ( 2002). Mechanical impact treatment on pulp fibers and their handsheet properties Palpu Chongi Gisul/Journal of Korea Technical Association of the Pulp and Paper Industry 34 (5), 56-62.

Seth, R. S. (2001). The difference between never-dried and dried chemical pulps. Solutions (Tappi), 1(1), 1-23. 
Sharmiza, A., Latifa, J., Mahmudin, S., \& Mohd Nor, M. Y. (2005). Suitability of locally planted kenaf for pulp and paper applications, Procedings of 3th USM-JIRCAS International Symposium. JIRCAS (eds. Tanaka R. and Cheng, L.H.) Tsukuba, pp.54-57.

Sood, Y. V., Pande, P. C., Tyagi, S., Payra, I., Nisha, \& A G Kulkarni, A. G. (2005). Quality improvement of paper from bamboo and hardwood furnish through fiber fractionation. Journal of Scientific \& Industrial Research 64, 299-305.

Stratton, R. A., \& Colson, N. L. (1990). Dependence of fiber/fiber bonding on some papermaking variables. Material Research Society Symposium, 197, 173-181.

Ververis, C., Georghiou, K., Christodoulakis, N., Santas, P., \& Santas, R. (2004). Fiber dimensions, lignin and cellulose content of various plant materials and their suitability for paper production. Industrial Crops \& Products, 19(3), 245-254.

Villar, J. C., Revilla, E., Go'mez, N., Carbajo, J.M., Simo'n, J.L. (2009). Improving the use of kenaf for kraft pulping by using mixtures of bast and core fibers. Industrial Crops and Products, 29, 301-307.

Wanrosli, W. D., Zainuddin, Z., \& Roslan, S. (2005). Upgrading of recycled paper with oil palm fiber soda pulp. Industrial Crops \& Products, 21(3), 325-329.

Watson, A. J., \& Dadswell, H. E. (1964). Influence of fiber morphology on paper properties 3. length diameter (1/d) ratio. Appita Journal, 17(6), 146-150.

Yang, Q., Zhan, H., Wang, S., Li, K., \& Fu, S. (2008). Bio-modification of eucalyptus chemithermomechanical pulp. Chemistry Engineering China Journal, 2(1), 28-33.

Table 1. A summary of results achieved by selective treatment of fractions

\section{Fractionation advantages}

Energy savings through selective refining of fractions

Quality improvements through selective refining of fractions

Quality improvements through multilayered sheet structure (pulp fractions in the individual layers)

\section{Reported by}

Shagaev \& Bergstöm 2005; Nazhad \& Sodtivarakul 2004; Pimley, 1999; Musselmann 1993; Wood 1991

Afra et al., 2009; Wandelt and Perlińska-Sipa, 2008; Alexandre et al., 2007; Wandelt et al., 2005; Sood et al., 2005; Koskenhely et al. 2005; Abubakr Said et al., 1995; Pimley, 1999; Kure et al., 1999; Sandberg et al. 1997; Musselmann, 1993; Wood 1991

Liang et al., 2007; Sood et al., 2005; Tubek-Lindblom \& Salmén, 2003; Vollmer, 1999; Meltzer 1998

Branvall et al. 2005; Vomhoff and Groundstrom, 2003

Potential benefits by separate bleaching of pulp fractions enriched in early wood and latewood fibers 